\title{
Spontaneous alternation in rats with lesions in the frontal lobes: An extension of the frontal lobe syndrome
}

\author{
I. DIVAC, R. G. E. WIKMARK, and A. GADE \\ Laboratory of Behavioral Physiology, Institute of Neurophysiology, University of Copenhagen, Denmark
}

\begin{abstract}
Bilateral lesions in the anteromedial neocortex or the associated part of the neostriatum abolished spontaneous alternation in rats; removal of the suprarhinal strip did not. The classical deficit of spatial choice following frontal-lobe injury is not an artifact of the learning paradigm, but can be extended to unconditioned behavior. Furthermore, the impairment is not restricted to food-reinforced or massed responses. The response-guiding role of the frontal lobe is of such wide generality in the laboratory that it can be expected to operate in the animal's usual environment as well.
\end{abstract}

Most research on the behavioral roles of the prefrontal cortex has dealt with conditioned behavior. Warren criticized this orientation as having failed to answer "the basic biological question: What are the functions of the behavior mediated by the prefrontal cortex in adapting animals to their usual environment?" (Warren, 1972, p. 584). The remedy recommended by Warren was naturalistic analysis of frontal-lobe functions.

The prefrontal cortex obviously did not evolve to enable animals to learn delayed response-type problems in the laboratory (Warren, 1972). On the other hand, delayed response-type tasks (notably delayed alternation) are sensitive to frontal-lobe injury in many different situations and in species of several lines of descent (Konorski, Teuber, \& Zernicki, 1972; Warren \& Akert, 1964; Wikmark, Divac, \& Weiss, 1973). This large and consistent body of data cannot be discarded as devoid of potential biological validity. Whereas a neuroethology of the prefrontal cortex is clearly needed, it may also be profitable to attempt to bridge the gap between the "frontal" tasks devloped by experimental psychologists, and the natural behavioral repertoire of the species.

Seligman (1970) has emphasized that animals are differently prepared to establish different associations: stimulus-response relations may be arranged along a continuum of "preparedness," ranging from innate reactions to specific events to associations which can be acquired only after extensive training or not at all. "Prepared" behaviors may be assumed to possess a high survival value for the species in its natural habitat, whereas "unprepared" or "counterprepared" reactions may be irrelevant or adverse to survival. Importantly, Seligman summarized some evidence suggesting that certain "laws" or learning apply only at certain levels of "preparedness." If, indeed, the nature of learning varies according to an animal's propensity for a particular kind of behavioral adaptation, it seems probable that structure-function relations may vary with "preparedness" as well. Unfortunately, all traditional "frontal" tasks represent behavior for which the animals are relatively "unprepared," i.e., a period of training invariably precedes mastery of the test. The purpose of the present study was to assess whether frontal-lobe injury interferes also with a highly "prepared" behavior, namely, spontaneous alternation in rats.

Spontaneous alternation is of interest in the present context because it shares many features with classical "frontal" tasks: the animal makes repeated spatial choices at one choice point in the face of the same external stimulus configuration. Spontaneous alternation behavior differs from delayed alternation, however, in being unconditioned; on the second exposure to an unbaited T-maze, $80 \%-90 \%$ of normal rats choose to enter the alley opposite to the arm visited on the first trial (Dember \& Fowler, 1958).

The rate of spontaneous alternation in three groups of brain-lesioned rats was studied here. The anteromedial neocortex, the anteromedial part of the neostriatum, or the suprarhinal neocortical strip were destroyed. Each region receives projections from the mediodorsal thalamic nucleus; the anteromedial cortex in turn projects to the anteromedial portion of the neostriatum (Leonard, 1969). Lesions in the anteromedial neocortex and neostriatum impaired delayed alternation in the apparatus employed here (Wikmark et al., 1973).

\section{METHOD}

Twenty-eight male Wistar rats were housed in groups of three or four with water and food available ad lib. Fifty days before the beginning of this experiment the rats received lesions in the anteromedial cortex (AMC: $\mathrm{N}=8$ ), the dorsal bank and lip of the rhinal sulcus $(\mathrm{Rh}: \mathrm{N}=6)$, or the anteromedial region of the neostriatum (NC: $\mathrm{N}=7$ ): in the remaining rats only the skin and galea were cut $(\mathrm{Co}: \mathrm{N}=7)$. Prior to the present experiment, the rats were trained in an operant chamber on acquisition and 


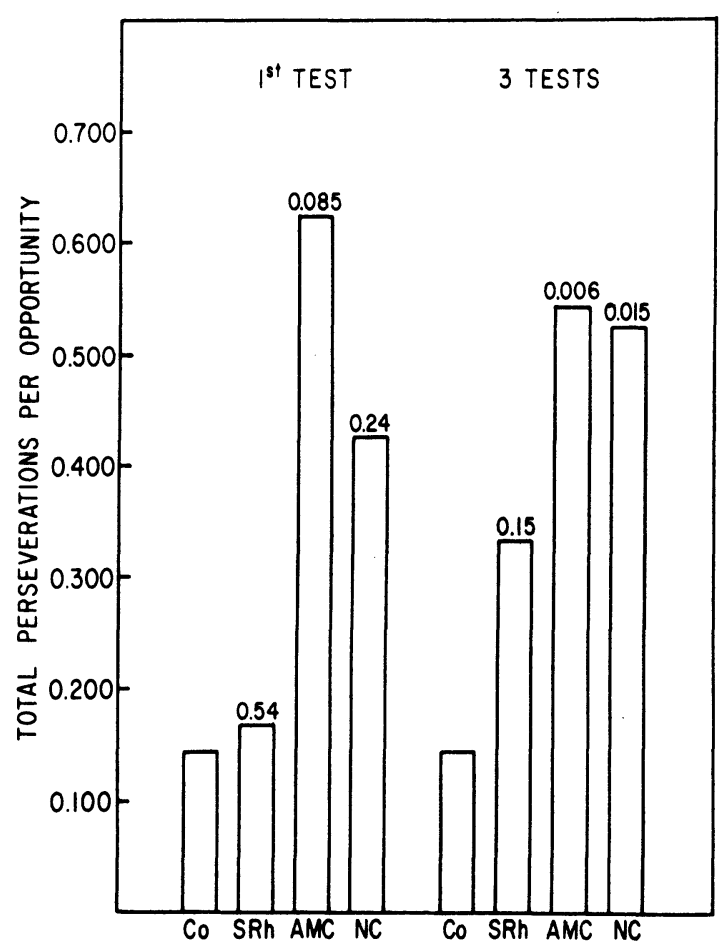

Figure 1. Proportion of instances of reentering the same arm on the second trial. The value $\mathbf{0 . 5 0 0}$ indicates that a group makes equal number of alternations and perseverations. The $p$ values of the differences from the Co group are given above each column (Fisher exact probability test).

extinction of a food-reinforced VI schedule, and their spontaneous locomotor activity was measured (Gade and Divac, in preparation). This testing terminated 3 days before the beginning of the present study.

\section{Apparatus and procedure}

The animals were tested in a T-maze described elsewhere (Wikmark et al., 1973). The goalboxes contained no food. Three tests were given, separated by 3-day intervals. Each test consisted of two identical trials. The rat was (1) placed in the startbox and released immediately, (2) enclosed in the chosen alley for $60 \mathrm{sec}$ with a Plexiglas door, (3) transferred to a transport cage for $15 \mathrm{sec}$, and (4) returned to the maze for a second trial. The tester did not know to which group an animal belonged.

\section{Surgery and histology}

The cortex was ablated by subpial suction and the neostriatum was coagulated stereotaxically. Deeply anesthetized rats were perfused, their brains were cut at 100 micra, and the lesions drawn under a photographic enlarger (for details, see Divac et al., 1975b, Wikmark et al., 1973).

\section{RESULTS}

\section{Anatomy}

The lesions are described and illustrated elsewhere (Divac et al., 1975). Briefly, the anteromedial cortex was ablated from the frontal pole to the level of bregma. The dorsal bank and lip of the rhinal sulcus were removed in the $\mathrm{Rh}$ group. The rest of the lateral neocortex and the medial part of the suprarhinal bank were left intact. Stereotaxic lesions destroyed the part of the neostriatum which receives projections from the anteromedial cortex (Leonard, 1969). The anteromedial neocortical and neostriatal lesions were symmetrical and almost identical to those which impaired delayed alternation and spatial reversals in earlier studies (Divac, 1971; Wikmark et al., 1973).

\section{Behavior}

As expected, neurologically intact rats usually alternated (Figure 1). Animals with suprarhinal decortication showed a slightly lower rate of alternation but did not differ significantly from controls (Fisher exact probability test was used for all statistical analysis). In contrast, the rats with lesions in the anteromedial cortex or the neostriatum alternated significantly less often than the normals (Figure 1).

The performance of the four groups can be more closely inspected in Table 1 . The decreased rate of alternation is seen in each of the three tests in Groups $\mathrm{AMC}$ and NC; Group Rh showed such an effect only on the second test. Animals with anteromedial lesions perseverated once or twice over three tests in accordance with expectation from a random distribution of responses. One animal in each neocortical group perseverated in all three tests; these animals did not differ from the others in their groups with respect to lesion size or site. No rat chose the same arm in all six trials, although some animals with anteromedial ablations showed a position preference. Group comparisons, however, revealed no reliable difference from the controls (Co vs. NC: $\mathrm{p}=.13$ ). The data do not permit a distinction between truly random ("unguided") responding and a mild tendency to either repeat responses or choose one side more often than the other.

\section{DISCUSSION}

Lesions in the anteromedial cortex or the neostriatum, which in an earlier experiment were found to impair conditioned alternation behavior in rats (Wikmark et al., 1973), interfered also with spontaneous

Table 1

Number of Rats Making Repetitive Choices

\begin{tabular}{llcccc}
\hline \multirow{5}{*}{ Perseverating } & & Co & AMC & NC & Rh \\
& & $\mathrm{n}=7$ & $\mathrm{n}=8$ & $\mathrm{n}=7$ & $\mathrm{n}=6$ \\
\cline { 2 - 6 } & Test 1 & 1 & 5 & 3 & 1 \\
& Test 2 & 1 & 4 & 3 & 4 \\
& Test 3 & 1 & 4 & 5 & 1 \\
Perseverating & Never & 4 & 0 & 0 & 2 \\
& Once & 3 & 4 & 4 & 3 \\
Entering the & Twice & 0 & 3 & 3 & 0 \\
same arm & Thrice & 0 & 1 & 0 & 1 \\
& 3 Times & 4 & 2 & 1 & 2 \\
& 4 Times & 3 & 5 & 3 & 4 \\
& 5 Times & 0 & 1 & 3 & 0 \\
& 6 Times & 0 & 0 & 0 & 0 \\
\hline
\end{tabular}


alternation. It seems likely, therefore, that the same frontal-lobe mechanisms which underlie comparatively "unprepared" spatial choices in situations such as delayed alternation (Wikmark et al., 1973), delayed responses (Kolb, Nonneman, \& Singh, 1974), and spatial reversals (Divac, 1971), are important also for presumably innate response tendencies. In other words, the frontal "association" cortex is not recruited solely for learned associations.

While the present finding extends the number of behaviors which appear to be subserved by the frontal lobes, it also reduces the number of potentially critical features of tests which are sensitive to frontal-lobe injury. Traditional "frontal" tasks are almost invariably food motivated (see an exception in Miles \& Rosvold, 1956). In contrast, the rats studied here were tested in an unbaited maze. Furthermore, "frontal" tasks typically involve massed trials, whereas the present rats were tested only for two trials each day. Thus, deficient “parsing' (Pribram \& Tubbs, 1967) cannot fully explain all spatial deficits seen after frontal-lobe injury (see also Wilson, Oscar, \& Gleitman, 1963). Presently available data indicate that the prefrontal cortex and the associated part of the neostriatum are important components of a response-guiding mechanism (Rosvold, 1968) which operates whenever repeated spatial choices are made in the absence of any external response-guiding cues at the moment of choice. This mechanism apparently plays a role in species-typical response patterns (present data), as well as in choices which are easily acquired (e.g., Divac, 1968), or painstakingly learned (e.g., Divac \& Warren, 1971), and seems to be rather independent of motivational state, stimulus configuration, and response requirements (e.g., Stamm, 1970). The mechanism is represented in all nonhuman mammals which have been investigated, occupying different ecological niches (Wikmark et al., 1973).

Several pathways lead into and out of the prefrontal cortex (Leonard, 1969; Nauta, 1972), but only some of them appear to be crucial for the spatial functions of the frontal lobe (for a discussion, see Wikmark et al., 1973). Lesions in the anterior part of the neostriatum presently abolished spontaneous alternation and previously impaired conditioned alternation (Wikmark et al., 1973) as well as spatial reversals (Divac, 1971). The effect of neostriatal lesions cannot be ascribed to undercutting of the prefrontal cortex (Divac, 1972) since neostriatal damage severely affected conditioned delayed alternation even in rats which relearned the task following frontal decortication (Wikmark \& Divac, 1973, in preparation). Destruction of the mediodorsal thalamus, on the other hand, impaired neither spontaneous alternation nor spatial reversals in rats (Tigner, 1974). structures implicated in the "frontal-lobe system" by Rosvold (1972) interfered with spontaneous alternation
(Dalland, 1970; Ellen \& Deloache, 1968; Stevens \& Cowey, 1973) as well as with spatial reversals (Nonneman, Voigt, \& Kolb, 1974; Samuels, 1972; Schwartzbaum \& Donovick, 1968; Srebro \& Divac, 1972; Thompson \& Langer, 1963). However, these deficits are not equivalent: rats with hippocampal or septal lesions perseverated in an unbaited T-maze but for different reasons (Dalland, 1970). In contrast, the rats with anteromedial lesions in the present study made statistically random choices. A qualitative analysis of the spatial deficits arising from damage to various interconnected brain formations may advance understanding of the information processing underlying uncued spatial choice.

Removal of the suprarhinal cortex did not significantly interfere with spontaneous alternation in this experiment. Even larger suprarhinal ablations impaired neither spatial delayed responses (Kolb et al., 1974), nor spatial reversals (Nonneman et al., 1974). While this pattern of results indicates that the ventrolateral part of the prefrontal cortex in rats plays no role in the spatial (possibly mnemonic, Goldman, Rosvold, Vest, Galkin, 1971) functions of the frontal lobes, the present data must be interpreted with caution due to the small size of the group.

\section{REFERENCES}

Dalland, T. Response and stimulus perseveration in rats with septal and dorsal hippocampal lesions. Journal of Comparative and Physiological Psychology, 1970, 71, 114-118.

Dember, W. N., \& Fowler, H. Spontaneous alternation behavior. Psychological Bulletin, 1958, 55, 412-428.

Divac, I. Effects of prefrontal and caudate lesions on delayed response in cats. Acta Biologiae Experimentalis, 1968, 28, 149-167.

Divac, I. $9,175-183.9,175-183$.

Divac, I. Neostriatum and functions of prefrontal cortex. Acta Neurobiologiae Experimentalis. 1972. 32, 461-477.

Divac, I., Gade, A., \& Wikmark, R. G. E. Taste aversion in rats with lesions in the frontal lobes: No evidence for interoceptive agnosia. Physiological Psychology, 1975, 3, 43-46.

Divac, I., \& Warren, J. M. Delayed response by frontal monkeys in the Nencki Testing Situation. Neuropsychologia, 1971, 9 , 209-217.

Ellen, P., \& Deloache, J. Hippocampal lesions and spontaneous alternation behavior in the rat. Physiology and Behavior, $1968,3,857-860$.

Goldman, P., Rosvold, H. E., Vest, B., \& Galkin, T. W. Analysis of the delayed alternation deficit produced by dorsolateral prefrontal lesions in the rhesus monkey. Journal of Comparative and Physiological Psychology, 1971, 2, 212-220.

Kolb, B. E., Nonneman, A., \& Singh, R. K. Double dissociation of spatial impairments and perseveration following selective prefrontal lesions in rats. Journal of Comparative and Physiological Psychology, 1974, 87, 772-780.

Konorski, J., Teuber, H.-L., \& Ziernicki, B. (Eds.), The frontal granular cortex and behavior. Acta Neurobiologiae Experimentalis, 1972, 32, 119-656.

Leonard, C. M. The prefrontal cortex of the rat. I. Cortical projection of the mediodorsal nucleus. II. Efferent connections. Brain Research, 1969, 12, 321-343.

Miles, J. E., \& Rosvold, H. E. The effect of prefrontal lobotomy in rhesus monkeys on delayed-response performance motivated by pain-shock. Journal of Comparative and Physiological Psychology, 1956, 49, 286-292.

Nauta, W. J. H. Neural associations of the frontal cortex. Acta Neurobiologiae Experimentalis, 1972, 32, 125-140.

Nonneman, A. J., Voigt, J., \& Kolb, B. E. Comparisons of behavioral effects of hippocampal and prefrontal cortex lesions in the rat. Journal of Comparative and Physiological Psychology, 1974, 87, 249-260.

Pribram, K. H., \& Tubbs, W. E. Short-term memory, parsing and the primate frontal cortex. Science, $1967,156,1765-1767$. 
Rosvold, H. E. The prefrontal cortex and caudate nucleus: A system for effecting correction in response mechanisms. In C. Rupp (Ed.): Mind as a tissue. New York: Harper \& Row, 1968. Pp. 21-38.

Rosvold, H. E. The frontal lobe system: Cortical-subcortical interrelationships. Acta Neurobiologiae Experimentalis, 1972, 32, 439-460.

Samuels, I. Hippocampal lesions in the rat: Effects on spatial and visual habits. Physiology and Behavior, 1972, 8, 1093-1098.

Schwartzbaum, J. C., \& Donovick, P. J. Discrimination reversal and spatial alternation associated with septal and caudate dysfunction in rats. Journal of Comparative and Physiological Psychology, 1968, 65, 83-92.

Seligman, M. E. P. On the generality of the laws of learning. Psychological Review, 1970, 77, 406-418.

Srebro, B., \& Divac, I. Successive position reversals in rats with septal and/or fronto-polar lesions. Physiology and Behavior, 1972, 9, 269-272.

Stamm, J. S. Dorsolateral frontal ablations and response processes in monkeys. Journal of Comparative and Physiological Psychology, 1970, 70, 437-447.

Stevens, R., \& Cowey, A. Effects of dorsal and ventral hippocampal lesions on spontaneous alternation, learned alternation, and probability learning in rats. Brain Research, $1973,52,203-224$.

Thompson, R., \& Langer, S. K. Deficits in position reversal learning following lesions of the limbic system. Journal of Comparative and Physiological Psychology, 1963, 56, 987-995

Tigner, J. C. The effects of dorsomedial thalamic lesions on learning, reversal, and alternation behavior in the rat. Physiology and Behavior, 1974, 12, 13-17.

Warren, J. M. Evolution, behavior and prefrontal cortex. Acta Neurobiologiae Experimentalis, 1972, 32, 581-593.

Warren, J. M., \& Akert, K. (Eds.), The frontal granular cortex and behavior. New York: McGraw-Hill, 1964.

Wikmark, R. G. E., \& Divac, I. Comparative studies of functional relations in the frontal lobes. Paper presented at the 81 st Annual Convention of the American Psychological Association, Montreal, 1973.

Wikmark, R. G. E., Divac, I., \& Weiss, R. Retention of spatial delayed alternation in rats with lesions in the frontal lobes. Implication for a comparative neuropsychology of the prefrontal system. Brain, Behavior and Evolution, 1973, 8, 329-339.

Wilson, A. W., Jr., Oscar, M., \& Gleitman, H. The effects of frontal lesions in monkeys upon widely-spaced delayed-response. Journal of Comparative \& Physiological Psychology, 1963, 56, 237-240.

(Received for publication September 10, 1974; accepted September $25,1974$. ) 